\title{
Increasing the required slip range of wound induction generator in wind power systems
}

\author{
Ali Dalabeeh ${ }^{1}$, Al-Mofleh Anwar², Tariq M. Younes ${ }^{3}$, Ayman Al-Rawashdeh ${ }^{4}$, Ayman Hindi $^{5}$ \\ ${ }_{1,2,4}$ Electrical Engineering Department, Al-Balqa Applied University, Jordan \\ ${ }^{3}$ Department of Mechatronics Engineering, Al-Balqa Applied University, Jordan \\ ${ }^{5}$ Najran University, College of Engineering, Najran University, KSA
}

\begin{tabular}{l} 
Article Info \\
\hline Article history: \\
Received Sep 19, 2019 \\
Revised Nov 20, 2019 \\
Accepted Feb 1, 2020 \\
\hline
\end{tabular}

\section{Keywords:}

Eddy current

Generators

Induction motors

Losses

Wind turbine

\begin{abstract}
Eddy currents losses in the rotor in high power generators do not allow operators, under high values of slip, to regulate voltage and control of reactive power flow. The paper presents a method that can accurately estimate the eddy current losses in electric machines with a less complicated procedure. The suggested method allows researchers to analyze and reduce the losses, and consequently, to improve the wind turbine induction generators efficiencies. The given approach, based on the conventional electric machine theory and the parameters supplied by the manufacturers, predicts the eddy current losses theoretically without the need of the measured material loss data or $\mathrm{BH}$ curve. Increasing the range of slip variation of induction motor can be achieved by using a rotor of two layers in the radial direction with different parameters. The first layer is a laminated layer of height (h), and the second is a solid (the rotor yoke). The computation of eddy current losses is useful to change the design of the machine to minimize the losses. This paper presents a detailed modeling of the effect parameters on the eddy current losses in wind turbine induction generator.
\end{abstract}

This is an open access article under the CC BY-SA license.

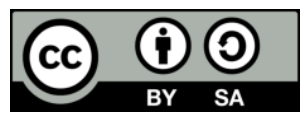

\section{Corresponding Author:}

Ali Dalabeeh,

Electrical Engineering Department, Faculty of Engineering Technology,

Al-Balqa Applied University, Amman 11134, Jordan.

Email: alidalabeeh@yahoo.com

\section{INTRODUCTION}

Wind energy is one of the fastest growing renewable technologies. It is regarded as one of the most widely utilized distributed energy resources in the world. Furthermore, wind generation is the most variations to other types of renewable energy [1]. The generated electric power and the loss in wind turbine generator system (WTGS) change w.r.t wind speed variations and so the efficiency and the capacity factor of the system are also changed.It is most important to analyze the losses characteristics of WG which is found from wind speed to capture more energy from the wind. Furthermore, the most of the losses in wind turbine system is non-linear losses. If used average wind speed to get the more profit but they may cause many errors [2].

The prime reason for the utilization of wind turbines to generate electrical power is that they produce very low $\mathrm{CO}_{2}$. Due to this fact they are regarded to be a clean and sustainable source of power, and they are contending with electric utilities in providing economical clean power in various parts of the world and help reducing climate change. Wind energy is used worldwide and several countries are building more and more wind turbine and integrating them into their electricity. Induction machines 
or synchronous and permanent magnet generators are generally employed for the electromagnetic conversion. [3]. Wind energy use depends on the means and variety of wind speeds in a given area [4].

Nowadays most of the world used large size Doubly-Fed Induction Generator (DFIG) systems due to their quality to operate at variable speed by using power electronic converters in rotor circuit [5]. If the wind speed increases then the Iron loss and flux density will decrease. But the generator real power and reactive power increases. The efficiency is important when comparing different systems because the losses reduce the average power produced by the wind energy converter and, thereby, they reduce the incomes [6,7]. The estimated losses in the generators at rated load of a $500 \mathrm{~kW}$ for wind turbines are shown in Table 1 [3]. The induction generator losses are calculated according to the conventional electric machine theory. The losses are copper losses, hysteresis and eddy current core losses, windage and friction losses, and additional losses. The copper losses depend on the currents, the hysteresis and eddy current core losses depend on the flux linkage and the frequency, the friction losses only depend on the generator speed, and the additional losses can be assumed to depend only on the current.

Table 1. Losses in the generators at rated load

\begin{tabular}{lccc} 
& \multicolumn{3}{c}{ Table 1. Losses in the generators at rated load } \\
& $\begin{array}{c}\text { Induction generator } \\
\text { (grid connected) }\end{array}$ & $\begin{array}{c}\text { Synchronous generator } \\
\text { (diode loaded) }\end{array}$ & $\begin{array}{c}\text { Directly driven PM generator } \\
\text { (diode loaded) }\end{array}$ \\
\hline Core losses & $1.5 \%$ & $1.5 \%$ & $1.2 \%$ \\
Copper losses, and Additional losses & $1.5 \%$ stator \& rotor & $1.15 \%$ stator & $3.5 \%$ stator \\
Friction,windage, and cooling losses & $0.5 \%$ & $0.5 \%$ & $1 \%$ incl.turbine bearing \\
Excitation losses & - & $0.75 \%$ & - \\
Total losses & $3.5 \%$ & $3.9 \%$ & $5.7 \%$ \\
\hline
\end{tabular}

Among various generators used to convert wind energy, the induction generator has attracted more attention due to its lower cost, lower requirement of maintenance, variable speed, higher energy capture efficiency, and improved power quality [7, 8]. However, such direct connection with grid would allow the speed to vary in a very narrow range and thus limit the wind turbine utilization and power output. On the other hand, the DFIG with variable-speed ability has higher energy capture efficiency and improved power quality, and thus dominates the large-scale power conversion applications. The generator is dedicated to the conversion between mechanical energy, which is captured by turbine rotor, and electrical energy. The generated electrical energy then needs to be regulated and conditioned to be connected to the power grid for use. However, the lower generator speed, and thus larger torque, requires more poles, larger diameter, and volume, and hence higher cost [9-18]. Through the control of rotor resistance, the slip of the generator is varied. The losses in electric machines consist of copper loss, mechanical loss, and core loss. According to previous studies, core losses constitute $20 \%-25 \%$ of the total losses in sinusoidal voltage fed machines. These losses further increase when the machine is fed with pulse width modulated variable speed drives [19]. Currently, core loss estimations are performed in finite element analysis (FEA) software packages using flux density waveforms in each element of the model.

These methods are based on Steinmetz equation and the loss separation principle, with the coefficients of the respective nonlinear equations determined using the core loss measurement data under certain conditions. When it comes to the electric machine core loss estimation, these models result in more than $100 \%$ estimation error in some cases, even at rated conditions, these models are very complex, they require detailed material information, and they are hard to integrate into the FEA software. Therefore, a better method that can accurately estimate and simplified the core losses in electric machines with a less complicated procedure is highly desirable [20]. Better understanding of loss components allowed researchers to analyze and reduce the losses, and consequently, to improve the machine efficiencies [2, 7, 19-22]. Thus, the two loss components, hysteresis and eddy current losses are caused by the same physical phenomena: any change in magnetization causes the domain walls to move, which induces eddy currents resulting in Joule heating [23-25]. It is a fact that hysteresis losses occur even at zero frequency. While macroscopic magnetization changes slowly, the magnetization inside the domain changes rapidly and thus induces eddy currents $[24,26]$. Therefore, separating losses into loss types such as hysteresis losses, eddy current losses and excess losses is an engineering-oriented empirical approach. The core losses are expressed as an exponential function depending on the peak magneticflux density and the frequency.

The aim of this paper is to predict the eddy current losses practically without the need of the measured material loss data or $\mathrm{BH}$ curve. The needed parameters are mostly supplied by the manufacturers or can be easily extracted from the manufacturers' loss measurement data. In summary; there is a wide range of available core loss models for estimating the core losses in electric machines. The Steinmetz Equation based models and the loss separation models are the most common models used for core loss estimations due to their simple structure and straightforward calculation procedures. The given 
work shows that the range of slip variation of induction motor can be increased by using a two layers rotor in the radial direction with different parameters. The first layer is a laminated layer of height (h), and the second a solid, the rotor yoke [27]. WTGS is of low cost in comparison with other generation systems using renewable energy. However, the electric power obtained from wind generators (WG) is not constant due to wind speed variations. The generated electric power and the loss in WTGS change corresponding to the wind speed variations, and consequently the efficiency of the system also change [28]. By using the presented method eddy current losses can be calculated quickly. The wind turbine induction generator is contributing more than $50 \%$ in wind power generation $[29,30]$. The computation of eddy current losses is useful to change the design of the machine to minimize the losses in order to expand the required slip range of the wind turbine induction generator.

\section{CALCULATION METHOD}

Eddy current loss determination requires knowledge of the magnetic material characteristics for all the different magnetic motor components. Iron losses comprise three components: eddy current loss, hysteresis loss and excess loss. Hysteresis loss is an effect that occurs within the ferromagnetic materials. Hence, material selection is minimizing the core loss. Iron losses depend on the fundamental frequency $f$, the peak value of the magnetic flux density $\mathrm{Bm}$, the conductivity of the material $\gamma$, the thickness of the lamination d, the slip $\mathrm{S}$ and the loss coefficients. Generally, the manufacturer of the magnetic sheets provides the value of iron loss in watts per kilogram for given values of magnetic flux density and frequency. Based on this knowledge the loss coefficients can be identified [31-35].

Eddy current losses are calculated in this paper. The induction motor is treated as an eddy current field problem. In eddy current field problems, the electric and the magnetic fields are coupled, because the field quantities are depending on the time variation; however, the displacement current density can be neglected [36]. The eddy current loss generated in the laminated core and in the rotor yoke can be calculated using the formula in (1) [28]. Eddy-current loss generated in the rotor yoke is the result of small circulating currents that are induced when the flux density changes in the magnetic material.

$$
\nabla B \boldsymbol{z}=\boldsymbol{J} \boldsymbol{S} \omega \boldsymbol{\gamma} \mu \boldsymbol{B z}
$$

where: $S=$ the slip of the induction machine.

$$
\begin{aligned}
& \omega=2 \pi f \\
& f=\text { System frequency } \\
& \gamma=\text { conductivity } \\
& \mu=\text { magnetic permeability } \\
& \text { Bz=Magnetic field }
\end{aligned}
$$

In the solid rotor with laminated layer the following assumptions are applied:

- The Magnetic field is uniform.

- The stator and rotor Magnetic permeability assumed to be constant.

- The first harmonic is only considered.

Under these assumptions, the whole losses in the solid rotor with a laminated layer from eddy currents after some manipulations can be determined using the following equation [28, 37]:

$$
P=\gamma \frac{\left(s \omega \tau_{1} d\right)^{2}}{12 \pi} \cdot P l B_{0}^{2}\left(1-e^{-2 k 1 h}\right)+\alpha_{p} \frac{(s \omega) \sqrt[1.5]{\gamma^{2}}}{\pi^{2} \sqrt{\mu_{2}^{2}}} \tau_{2}^{3} P l k_{\lambda} \cdot B_{0}^{2} \cdot e^{-2 k 1 h}
$$

where: $\tau=$ The pole pith in meters

$1=$ The rotor length in meters

$\mathrm{d}=$ The thickness of the rotor lamination inmeters

$\mathrm{h}=$ Height of the rotor slots in meters

\section{RESULTS AND DISCUSSION}

Eddy current losses calculations were held on a wind turbine induction generator [38-39] a rated stator power (at unity power factor) $S_{n s}=2 \mathrm{MW}$, at $690 \mathrm{~V}, f=50 \mathrm{~Hz}$. $S_{\max }= \pm 0.25$, and a rated ideal speed $=1500 \mathrm{rpm}$, number of poles $(2 \mathrm{p})=4$, efficiency $=95 \%$, The stator outer diameter $=0.8 \mathrm{~m}$, The pole pitch ( $\tau=0.4 \mathrm{~m}$, The design current density $=6.5 \mathrm{~A} / \mathrm{mm}^{2}, \mathrm{~B}_{0}=1.5 \mathrm{~T}$, The rotor length $\left(\mathrm{L}_{\mathrm{i}}\right)=0.52 \mathrm{~m}$, assuming that $\gamma=1.25 * 10^{6}, \mu=4000$, the rated rotor power (at unity power factor) $S_{n r}=S_{n s} * S_{\max }=0.5 \mathrm{MW}$. 
Based on the rotor material, rotor dimension, and the current density, the allowable eddy current loss in the rotor is estimated to be around $38 \mathrm{Kw}$. Using (2) the total eddy current losses in the rotor can be calculated and the results are shown in Figures 1-4. Figure 1 shows that the eddy current losses reached the maximum limit when the the rotor is solid $(\mathrm{h}=0)$, in this case, it is clear that the induction generator operates safely in the slip range between 0 and 0.03 only. If the generator operates outside this range (at higher speeds), an excessive heat produced in the rotor, that should be dissipated outside the machine, in case of poor cooling system, the machine may uncapable to dissipate the generated rotor heat completely to the outside of the machine. So, a conclusion can be made as follows: if the rotor is solid constructed without a lamination layer, then, the wind power induction generator could be operated in a very limited range of wind speed changes.

Figure 2 shows an opposite case to that shown in Figure 1 . Theoretically if $h=\tau=0.40 \mathrm{~m}$, the eddy current losses in the rotor are minimum, the slipe range of the generator operation here is increased, which means that the generator could work with wide range of wind speeds. the case of $h=\tau$, is an unpractical case from the machine construction overview, but the rotor could be constructed with $h$ less than $\tau$ (rotor of two layers solid and laminated layers), then the eddy current losses decreases and the slip range of the generator increases.

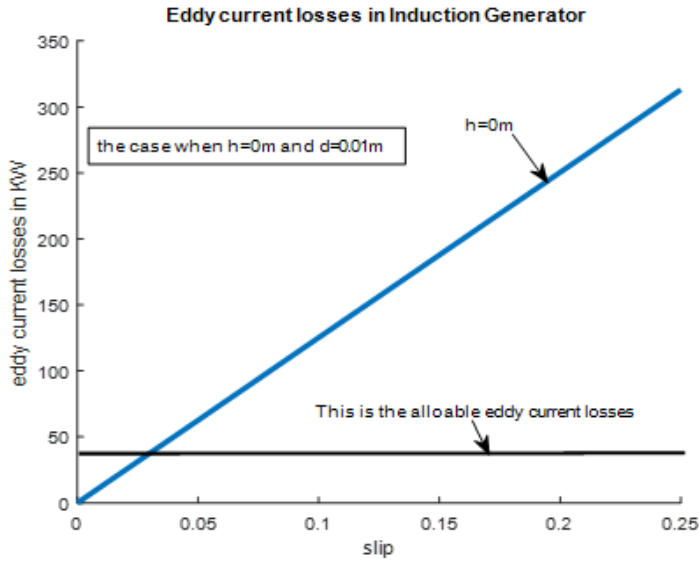

Figure 1. Eddy current losses $\mathrm{d}=0.01 \mathrm{~m}$

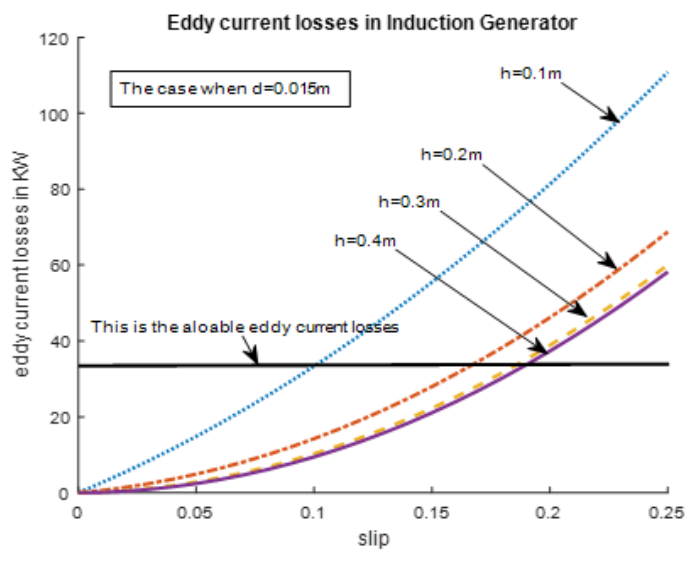

Figure 3. Eddy current in induction generator $(\mathrm{d}=0.015)$

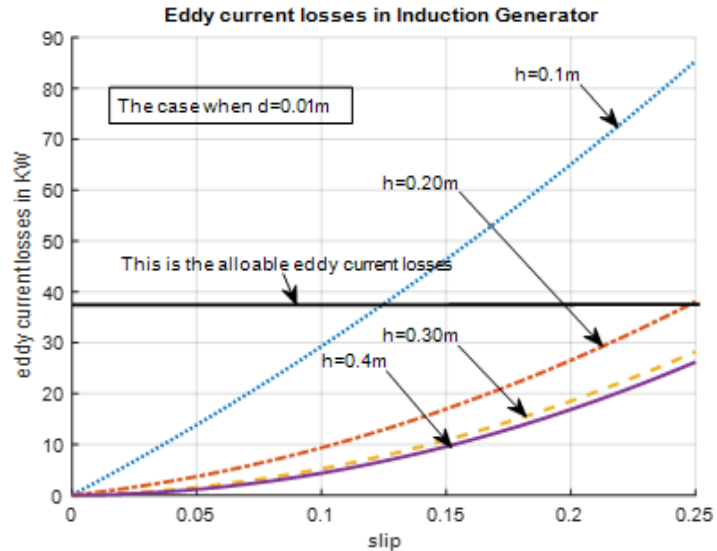

Figure 2. Eddy current losses $\mathrm{d}=0.01 \mathrm{~m}$

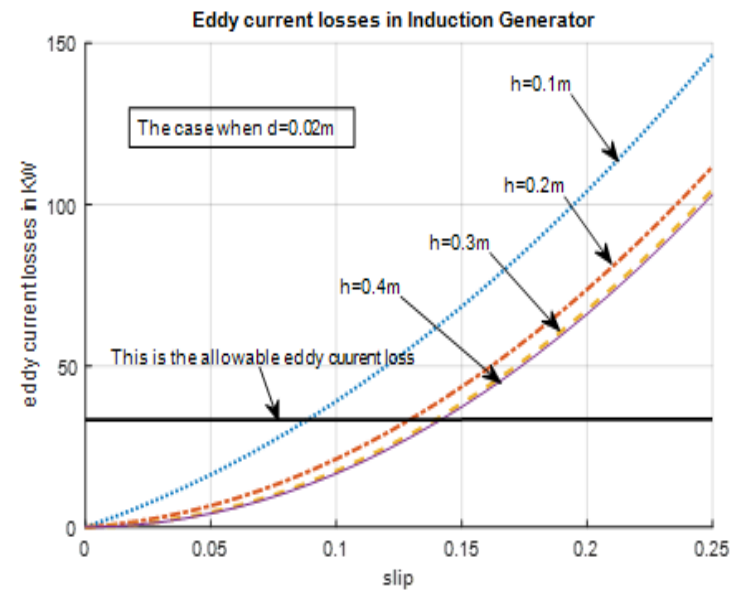

Figure 4. Eddy current in induction generator $(\mathrm{d}=0.02)$

Figures 1, 2, and 3 clearly show that the operation condition of the generator could be changed depending on the selected values of $\mathrm{d}$ and $\mathrm{h}$. for instance, if $\mathrm{d}=0.02 \mathrm{~m}$ and $\mathrm{h}=0.2 \mathrm{~m}$ then the induction generator works in a wide slip range which can be extended to a range of 0.2 without exceeding the allowable

Increasing the required slip range of wound induction generator in wind power systems (Ali Dalabeeh) 
limit of the eddy current losses ( thermal limit) in the rotor, and the machine with the provided cooling system works safely at wide range of variation of wind speeds. Close sight to Figure 4 , with $\mathrm{d}=0.015 \mathrm{~m}$ and $\mathrm{h}=0.3 \mathrm{~m}$, the slip reaches the point of 0.2 , which is a desirable value of operation for wind turbine induction generators systems especially in areas where the wind speed varies from low speeds $(3 \mathrm{~m} / \mathrm{s})$ to high speeds $(>14 \mathrm{~m} / \mathrm{s})$, the case that is encounterd in many places of the world and Jordan could be taken as an example [4].

\section{CONCLUSION}

The integration of wind turbine induction generators with electrical power systems requires a change of slip range. The research work showed that there is a possibility of increasing the range of the slip using a laminated layer in the solid rotor in the wind turbine induction generators. This can make the induction generator to operate in an extended slip range without exceeding the allowable eddy current losses limit. Since the slip is allowed to change, then a machine, with a cooling system, would work safely at a wid range of wind speed variation. Therefore, the use of solid rotor with a laminated layer in induction generators with a fixed voltage and frequency is one approach of using high power generators in power systems with high speed variation.

\section{REFERENCES}

[1] Seyed Mohsen, Mousavi Khormandichali, Mehrdad Ahmadi Kamarposhti, "Optimal placement of wind generation units in order to increase revenues and reduce the imposed costs in the distribution system considering uncertainty," International Journal of Electrical and Computer Engineering (IJECE), vol. 9, no. 6, pp. 4524-4539, Dec. 2019.

[2] P. M. Anderson and A. Bose, "Stability Simulation Of Wind Turbine Systems," in IEEE Transactions on Power Apparatus and Systems, vol. PAS-102, no. 12, pp. 3791-3795, Dec. 1983

[3] Hacil Mahieddine, Laid Zarour, Louze Lamri, Nemmour Ahmed Lokmane, "Developing a grid-connected DFIG strategy for the integration of wind power with harmonic current mitigation," International Journal of Electrical and Computer Engineering (IJECE), vol. 9, no. 5, pp. 3905-3915, October 2019.

[4] Ahmed Badawi, Nurul F. Hasbullaha, and others, "Evaluation of wind power for electrical energy generation in the Mediterranean coast of Palestine for 14 years," International Journal of Electrical and Computer Engineering (IJECE), vol. 9, no. 4, pp. 2212-2219, August 2019.

[5] Ali Salameh Khraiwish Dalabeeh, "Wind Energy Using Doubly Fed Induction Generator," International Journal of Engineering and Innovative Technology (IJEIT), vol. 3, no. 1, pp. 446-450, July 2013.

[6] Anders Grauers, "Efficiency of three wind energy generator systems," in IEEE Transactions on Energy Conversion, vol. 11, no. 3, pp. 650-657, Sept. 1996.

[7] Ali S. Khraiwish Dalabeeh, "Techno-economic analysis of wind power generation for selected locations in Jordan," Renewable Energy, vol. 101, pp. 1369-1378, Febuary 2017.

[8] Stiebler M., "Wind Energy Systems for Electric Power Generation," Springer: Renewable and Green Energy, ISBN: 978-3-540-68765-8, 2008.

[9] Ahlström A., "Simulating Dynamical Behaviour of Wind Power Structures," Licentiate Thesis, Royal Institute of Technology Department of Mechanics, 2002.

[10] Al Jabri, A. K., Alolah, A. I., "Limits on the performance of the three-phase self-excited induction generators," in IEEE Transactions on Energy Conversion, vol. 5, no. 2, pp. 350-356, June 1990.

[11] Al Jabri, A. K., Alolah, A. I., "Capacitance requirement for isolated self-excited induction generator," in Electric Power Applications, IEE Proceedings B (see also IEE Proceedings-Electric Power Applications), vol. 137, no. 3, pp. 154-159, June 1990.

[12] Alolah, A. L., Alkanhal, M. A., "Optimization-based steady state analysis of three phase self-excited induction generator," in IEEE Transactions on Energy Conversion, vol. 15, no. 1, pp. 61-65, March 2000.

[13] Alnasir, Z., Kazerani, M., "An analytical literature review of stand-alone wind energy conversion systems from generator viewpoint," Renewable and Sustainable Energy Reviews, vol. 28, pp. 597-615, December 2013.

[14] Sam, K. N., Kumaresan, N., Gounden, N. A., Katyal, R., "Analysis and Control of Wind-Driven Stand-Alone Doubly-Fed Induction Generator with Reactive Power Support from Stator and Rotor Side," in Wind Engineering, vol. 39, no. 1, pp. 97-112, February 2015.

[15] Kheldoun, A., Refoufi, L., Khodja, D. E., "Analysis of the self-excited induction generator steady state performance using a new efficient algorithm," in Electric Power Systems Research, vol. 86, pp. 61-67, May 2012.

[16] Nigim, K., Salama, M., Kazerani, M., "Identifying machine parameters influencing the operation of the self-excited induction generator," in Electric Power Systems Research, vol. 69, no. S 2-3, pp. 123-128, May 2004.

[17] Wang, L., Lee, C. H., "A novel analysis on the performance of an isolated self-excited induction generator," in IEEE Transactions on Energy Conversion, vol. 12, no. 2, pp. 109-117, June 1997.

[18] Kersting, W. H., Phillips, W. H., "Phase Frame Analysis of the Effects of Voltage Unbalance on Induction Machines," in IEEE Transactions on Industry Applications, vol. 33, no. 2, pp. 415-420, March-April 1997. 
[19] Sergey E. Zirka, Yury I. Moroz, Philip Marketos, Anthony J. Moses, "Evolution of the loss components in ferromagnetic laminations with induction level and frequency," in Journal of Magnetism and Magnetic Materials vol. 320, no. 20, pp. e1039-e1043, October 2008.

[20] Burak Tekgun, "Analysis, measurement and estimation of the core losses in electrical machines," A Dissertation Presented to The Graduate Faculty of The University of Akron, December 2016

[21] E. Dlala, A. Belahcen, J. Pippuri, and A. Arkkio, "Interdependence of hysteresis and eddy current losses in laminated magnetic cores of electrical machines," in IEEE Transactions on Magnetics, vol. 46, no. 2, pp. 306-309, Feb. 2010.

[22] D. L. Atherton and Jiles, D.C., "Effects of stress on ferromagnetic of steel," NDT International, vol. 19, no. 1, pp. 15-19, Febuary 1986

[23] A. Krings, S. A. Mousavi, O. Wallmark, and J. Soulard, "Temperature influence of NiFe steel laminations on the characteristics of small slotless permanent magnet machines," in IEEE Transactions on Magnetics, vol. 49, no. 7, pp. 4064-4067, July 2013.

[24] A. Krings and J. Soulard, "Overview and Comparison of Iron Loss Models for Electrical Machines," in Journal of Electrical Engineering, vol. 10, no. 3, pp. 162-169, May 2010

[25] C. D. Graham, "Physical origin of losses in conducting ferromagnetic materials," Journal of Applied Physics, vol. 53, no. 11, pp. 8276-8280, 1982.

[26] J. Reinert, A. Brockmeyer, and R. W. A. A. De Doncker, "Calculation of losses in ferro- and ferromagnetic materials based on the modified Steinmetz equation," in IEEE Transactions on Industry Applications, vol. 37, no. 4, pp. 1055-1061, July-Aug. 2001.

[27] A. Krings, "Iron losses in electrical machines-Influence of material properties, manufacturing processes, and inverter operation," Thesis, KTH Royal Institute of Technology, 2014.

[28] I. M. Postnikov, "Theory and methods of calculations of asynchronous turbine generators, (in Russian: Теория и методы расчета асинхронных турбогенераторов)," Book, Editor in Chief-Kiev, Naookova dooma, pp. 176, 1977.

[29] S. M. Muyeen, "Calculation Method of Losses and Efficiency of Wind Generators," Wind Energy Conversion Systems, Green Energy and Technology, pp 25-51, January 2012.

[30] Nikita T, K. Manickavasagam, Sachin S, "Computational Analysis on Doubly Fed Induction Generator to determine Core Loss under normal and Low Voltage Ride Through (LVRT) Condition," 2017 International Conference on Technological Advancements in Power and Energy ( TAP Energy), Kollam, pp. 1-6, 2017.

[31] Islam, M. J., Khang, H. V., Repo, A. K. and Arkkio, A., "Eddycurrent loss and temperature rise in the form-wound stator winding of an inverter-fed cage induction motor," in IEEE Transactions on Magnetics, vol. 46, no. 8, pp. 3413-3416, Aug. 2010.

[32] Ionel D. M., Popescu M., Cossar C. et al., "A general model for estimating the laminated steel losses under PWM voltage supply," in IEEE Transactions on Industry Applications, vol. 46, no. 4, pp. 1389-1396, July-Aug. 2010.

[33] Boglietti A., Cavagnino A., Ionel D.M. et al., "A general model to predict the iron losses in inverter fed induction motors," 2009 IEEE Energy Conversion Congress and Exposition, San Jose, CA, pp. 1067-1074, 2009.

[34] Cassat A., Espanet C., Wavre N., "BLDC motor stator and rotor iron losses and thermal behavior based on lumped schemes and 3D FEM analysis," in IEEE Transactions on Industry Applications, vol. 39, no. 5, pp. 1314-1322, Sept-Oct. 2003.

[35] Kohan N.A., Abbaszadeh K., "Influence of no sinusoidal flux waveform on transformer design methodology," 20101 st Power Electronic \& Drive Systems \& Technologies Conference (PEDSTC), Tehran, Iran, pp. 57-62, 2010.

[36] Chen Y., Pillay P., "An improved formula for lamination core loss calculations in machines operating with high frequency and high flux density excitation," Conference Record of the 2002 IEEE Industry Applications Conference. 37th IAS Annual Meeting (Cat. No.02CH37344), Pittsburgh, PA, USA, pp. 759-766, vol. 2, 2002.

[37] Daniel Marcsa, "Induction Motors Simulation by Finite Element Method and Different Potential Formulations with Motion VoltageTerm," Thesis Department of Automation Laboratory of Electromagnetic Fields Szechenyi Istvan University, 2008.

[38] R. C. Bansal, "Three-phase self excited induction generator: An overview," in IEEE Transactions on Energy Conversion, vol. 20, no. 2, pp. 292-299, June 2005.

[39] Ion Boldea, "Wound-Rotor Induction Generators: Design and Testing from: Variable Speed Generators," October 2015.

\section{BIOGRAPHIES OF AUTHORS}

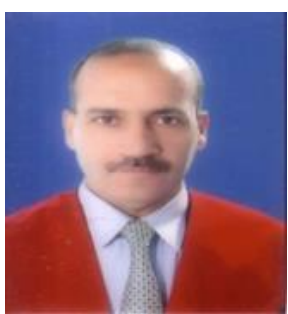

Ali S. K. Dalabeeh received his bachelor degree in electrical power engineering from Alleppo University/Engineering College/Syria in 1981 and $\mathrm{Ph}$. D in electrical engineering from Moscow power Institute in 1988. Currently he is an associate professor in electrical engineering department/Faculty of Engineering Technology/Al-Balqa Applied University. his research interests include renewable energy, energy efficiency, and deregulation in electrical power systems. 

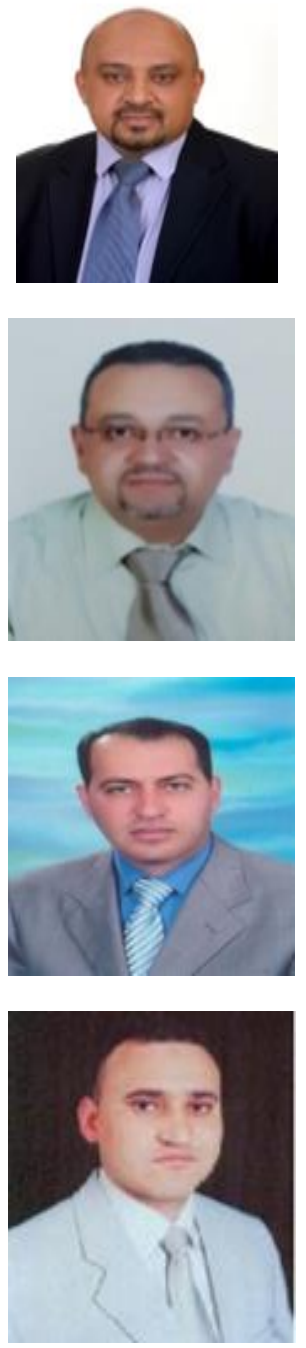

Anwar Al-Mofleh received his B. Sc and MSc from Byelorussian Polytechnic academy in 1993.He is currently, working as lecturer in Al-Balqa Applied University in Jordan and as candidate for $\mathrm{PhD}$, at the fields of power and energy efficiency E-mail address: anwaralmofleh@yahoo.com

Tariq M. Younes was born in Irbid, Jordan, in 1974. He received the bachelor and Master Degrees in Biotechnical and medical apparatus and systems Engineering from Tver State Technical University (Russian Federation) in 1998, and Ph. D degree in Instrumentation and measurement from Moscow State University of Environmental Engineering in 2004. In 2004, he joined the Department of Computer Engineering, Faculty of Engineering Technology Al Balqa Applied University, as a part time Lecturer, and in 2005 he became a full-time lecturer at the same department. Since September 2007, he has been with the Department o f Mechatronics Engineering at the same university, where he was an Assistant Professor, and he became an Associate Professor in 2012.

Dr. Ayman Y. Al-Rawashdeh PhD. Mechatronics. Eng, was born on 01 January 1970 in Jordan. He obtained diploma degree in 1995 and $\mathrm{PhD}$ degree in 2008 in the field of Mechatronics Engineering. Currently he works as an Assistant Professor at the Electrical Department, Faculty of Engineering Technology, Al-Balqa Applied University, Jordan. His main interest is renewable energy and drive system analysis and simulations

Ayman T. Hindi received his B. S from Vinnitsa Technical University in 1995 and $\mathrm{Ph} . \mathrm{D}$ in electro engineering science from Vinnitsa Technical University in 2004.Currently he is an assistance professor in electrical engineering department in Najran University. His research interests include compensation of reactive power energy and consumption in electric installation and systems 